\title{
Meeting the looming policy challenge of sea-level change and human migration
}

\author{
Minimizing the adverse consequences of sea-level change presents a key societal challenge. New modelling is \\ necessary to examine the implications of global policy decisions that determine future greenhouse gas emissions \\ and local policies around coastal risk that influence where and how we live.

\section{J. Wrathall, V. Mueller, P. U. Clark, A. Bell, M. Oppenheimer, M. Hauer, S. Kulp, E. Gilmore, H. Adams, R. Kopp, K. Abel, M. Call, J. Chen, A. deSherbinin, E. Fussell, C. Hay, B. Jones, N. Magliocca, E. Marino,} A. Slangen and K. Warner

$\mathrm{C}$ urrent and future sea-level rise and the accompanying increase in sealevel extremes (collectively, sea-level change) present a key challenge to coastal inhabitants and others living in destinations where retreating coastal migrants may settle over coming decades to centuries ${ }^{1}$. Although the physical processes that lead to coastal inundation are crucial in triggering migration decisions, the key dimensions of human mobility resulting from sea-level change - the number of displaced people and migrants, the forms of mobility that people use, the timing of migrations, their likely destinations and the socioeconomic condition of their departures and arrivals - are largely dependent on global policy decisions that determine future greenhouse gas emissions, and on local policies around coastal risk that influence where and how we live.

The interaction of sea-level change, various forms of human mobility and the intervening influence of policy raises questions whose answers could inform local planners and national decision-makers, as well as the general population facing this challenge. Figure 1 conceptually depicts the possibility space of sea-level change and human migration and the intervening role of policies, which may simultaneously drive a diversity of outcomes that can be explored and tested in models. Unprotected areas in low-elevation flood plains face a knowable probability of sea-level change and associated frequency of flooding, largely a product of extreme high tides and storm surges, similar under all emissions scenarios to the year 2050 (Fig. 1a). As sea-level change progresses, new exposure is likely to drive multiple simultaneous migration dynamics, even as a diversity of policies act as intervening factors (Fig. 1b). By 2100, different emissions scenarios produce diverging sea-level change trajectories, with corresponding coastal risks that will probably trigger adaptation strategies, namely coastal protection, accommodation and/or retreat, which may influence subsequent migration dynamics (Fig. 1c).

We need to know which coastal regions migrants will leave as sea level rises, and the destinations towards which migration will increase. What are feasible interventions that sending and receiving jurisdictions can introduce to influence migration, including adaptation measures to protect coastlines and accommodate infrastructure, but also migration incentives such as income credits, housing subsidies and public services in safer environments? How sensitive is migration induced by sea-level change to macro-level factors, such as interest rates, taxes, social services and entry quotas? What are the demographic and socioeconomic characteristics of future migrants, how do they differ from today's migrants, and how do migrants' policy demands differ in areas such as public health, education, housing and income?

What makes addressing these questions particularly daunting is the lack of a historical analogue for the projected magnitude of sealevel change ${ }^{1}$. New modelling can address this issue. Planners in local jurisdictions have long used 'top-down' spatial and economic models of urban growth to estimate the effect of specific regulatory, zoning or economic policies on future populations $s^{2}$. The more recent development of 'bottom-up' models, such as agent-based models (ABMs), now allows researchers to account for factors that affect human behavioural responses, although these are difficult to quantify at scale, such as individuals' aversions to uncertainty or attachment to their birth location ${ }^{3}$. Combining top-down and bottom-up modelling approaches may allow a more comprehensive means to examine the response of complex, emergent human dynamics, such as the effect of adaptation interventions on the coast.

\section{Policy as a determinant of dynamics} In its various forms, migration is a fundamental human strategy for improving livelihoods, wealth and welfare, reducing household risk, and recovering from economic and environmental disruptions ${ }^{3}$. Systems of migration emerge over time within a broader political, economic, social and demographic context in which an environmental factor such as sea-level change may act as an intervening influence on these other contextual factors or as a direct driver of migration independent of these other factors ${ }^{4}$.

The environmental consequences of sealevel change include increasingly frequent and hazardous flooding, storm surges, soil and water salinization, coastal erosion and permanent inundation ${ }^{5-7}$. The decision to migrate in response to sea-level change sits along a continuum between forced and free migration ${ }^{4}$. A range of socioeconomic impacts resulting from sea-level change may also trigger migration, including the destruction of infrastructure, the loss of livelihoods, a slow recovery of housing following disaster ${ }^{8}$, or prospective changes in the expected return on coastal livelihoods or real estate investments in response to actual impacts or anticipated sea-level change?

New patterns of migration triggered by sea-level change could take a multitude of forms, such as displacement, short-distance, seasonal or permanent migration (Fig. 1b), which would be likely to fold into existing systems of migration $^{4,8}$. For example, in agricultural societies undergoing industrialization and urbanization, where workers are transitioning from farm to urban wage labour, increasingly linking rural communities to cities, a decline in rural livelihoods due to salinization of soils and groundwater may simply accelerate existing urbanization ${ }^{10}$. Sea-level triggers are more likely to influence the timing and volume of ongoing migration rather than produce new patterns of migration without historical precedent $t^{4,8}$.

Policies, at local, national and international levels, applying to different populations, exert a strong intervening 
Exposure and adaption over time

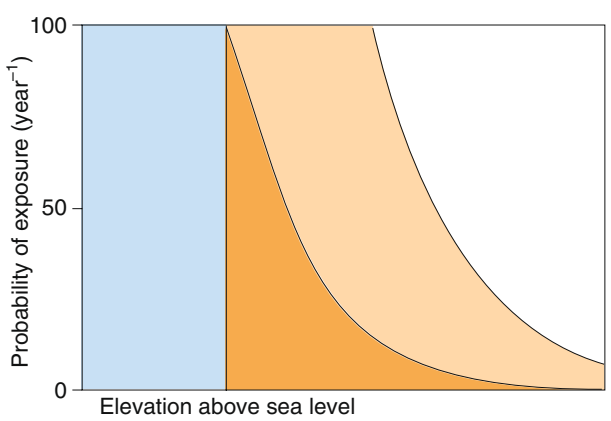

b

Near-term interactions of sea-level change migration and policy

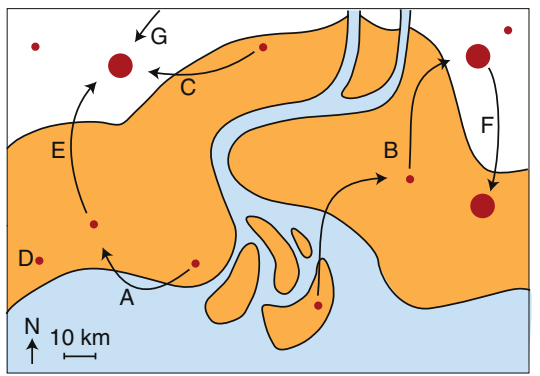

Interactions of sea-level change, migration and adaptation policy over time

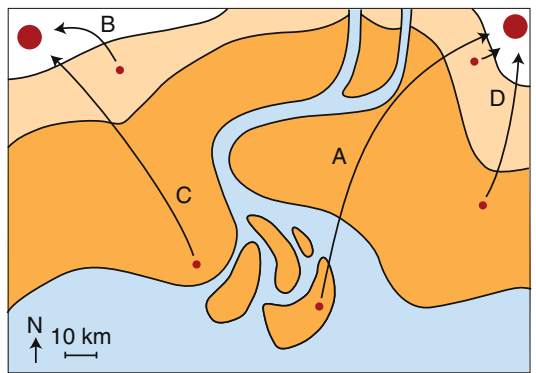

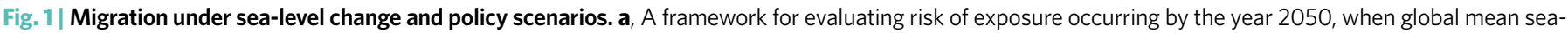

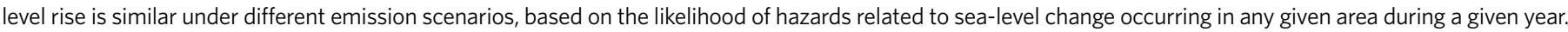
Mean sea level is indicated by the border between blue and orange regions. b. Exposure and migration dynamics that may emerge simultaneously in this period, their various triggering mechanisms and potential policies that may act as intervening factors. Migration is depicted (arrows) between potential destinations (red circles, the size of which correspond to rising and falling rates of migration). In the short term, policy may simultaneously influence various forms of mobility and migration at sea level including (A) short-distance, temporary or seasonal migration, (B) urbanization in coastal cities, (C) permanent migration from rural areas, (D) mobility traps, (E) prospective migration in advance of impacts, (F) short-term 'climate gentrification' of high-risk areas and (G) background pro-coastal migration. c, The possibility space for one projection of sea-level change under an unspecified emission scenario at the year 2100 , with associated adaptation interventions and migration outcomes. Areas in flood plains will be inundated with increasing frequency (dark orange), and new areas formerly above the annual flood plain will experience intensifying risk (orange). Adaptation interventions will increasingly affect migration dynamics, including ( $A$ ) the concentration of

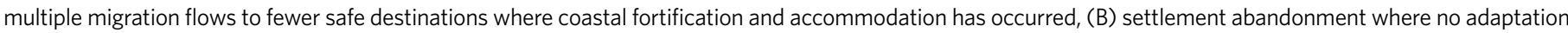

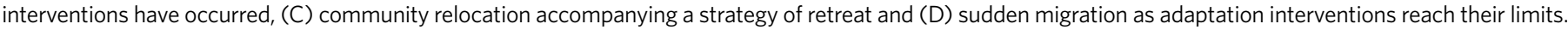

influence on migration, and will continue to do so even as sea-level change occurs (Fig. 1b). Policy can impose or remove physical, legal and bureaucratic barriers to both internal and international migration $^{11}$, enhance or eliminate access to social services for migrants ${ }^{12}$, or facilitate or obstruct transfers of funds for the establishment of networks that facilitate subsequent migration ${ }^{13}$. Economic policies such as sectoral or regional subsidies and interest-rate changes may indirectly affect labour market attractiveness to migrants, further influencing migration ${ }^{14}$. Migrants themselves may also select destinations based on policies such as public services, infrastructure provisioning, tax advantages, loans or incentives.

Public interventions aimed at adaptation to sea-level change likewise have implications for migration, including protecting coastal settlements, accommodating populations and the infrastructure they rely on to coastal hazards, and decisions to retreat from vulnerable areas ${ }^{15,16}$. Over time, investments in coastal adaptation could reconfigure how and when migration occurs (Fig. 1c). For example, new local policies in Norfolk, Virginia, USA include zoning for firstfloor elevation of residences in flood-prone areas, and incentives for developers to build new housing in flood-safe areas ${ }^{17}$. Still, adaptation policies may negatively impact the attributes of coastal places that people value culturally and economically, affecting their willingness to migrate ${ }^{18}$.

Unexpected feedbacks between sealevel change, policy and migration may also emerge. The availability of protective infrastructure, disaster insurance or other social protections could mediate household vulnerability to sea-level change, encourage people to remain in high-risk areas and alter people's willingness to invest privately in adaptation. Owing to the high social and economic costs of migration, some demographic groups, including the elderly and disabled, may become 'trapped' in vulnerable places ${ }^{18}$, altering demand for regular public services such as primary education and healthcare. The concentration of low-mobility populations in high-risk locations may eventually require costly policy interventions, such as assisted evacuation and resettlement. Other feedbacks may emerge in destinations far from the coastline, as migrants moving to safer locations alter job market competition and demand for housing and public services.

The relative influence of policy interventions on migration is a key source of uncertainty in future projections. It is particularly difficult to anticipate how policy will be employed at different times and across different spatial and administrative scales relative to sea-level change ${ }^{19}$. The central issue is that in many jurisdictions, policy is beholden to political processes in which decision-makers devise and revise policy affecting migrants with a view to maximizing gains and minimizing losses to their jurisdictions and political allies ${ }^{20}$, often in the short term, but with long-term implications for the treatment of migrants.

\section{Sea-level change and migration}

Projections about future migration dynamics must address the diversity of local impacts from sea-level change, the heterogeneity of migrants' decision-making across social contexts, and the uncertainty originating from policy alternatives. Projections of future migration are typically based on empirical models which use available data to quantify relationships between migration and other factors believed to influence location choice, such as wealth, wage differentials across locations, and exposure to risk ${ }^{2,21}$. In particular, regression models have been used to evaluate the effect of future climate hazards on migration based on historical migratory responses to environmental impacts ${ }^{6}$. However, these models are particularly limited for studying migratory responses to sea-level change owing to the lack of historical exposure to expected coastal hazards, with the exception of places experiencing natural and anthropogenic subsidence. Moreover, past models have assumed that location choice is continuous and constant over time, even though future sea-level change may directly affect the habitability and productivity of many locations simultaneously over time, 
eliminating them from the set of possible migration destinations. Models should therefore be able to evaluate changes in migration as sea-level migrants arrive in safer locations, congesting housing and labour markets, and diminishing the expected quality-of-life of other migrants who may then revise their location preferences. Evolving future sea-level change may influence migration feedbacks in more nonlinear, dynamical ways than are simulated in empirical models.

Equilibrium, or top-down, models are designed with an understanding of underlying structural mechanisms linking key system-level variables. These have the advantage of enabling quantitative projections of future behaviour in situations where a ceteris paribus assumption is not expected to apply. Computable general equilibrium (CGE) models, for example, can be used to quantify direct and indirect macro-economic effects of sea-level change on housing, labour, trade and other markets ${ }^{22}$. Within CGE modelling frameworks, an exogenous shock can be introduced to simulate how a change in policy may affect the direct and indirect impacts of sea-level change on migration, both push and pull factors. Local and regional planners can use CGE to examine coastal shocks and viability of, for example, a zoning law to redirect future climate migration patterns from one destination to another. Thus far, however, most CGE models have largely focused on quantifying the impacts of climate change and/or mitigation policy and less on the role of adaptation ${ }^{23}$.

A third class of models involve bottom-up simulations of complex adaptive systems. Prominent in this class are ABMs which, like CGE models, allow for the investigation of the dynamics of migration and the transformation of these systems following policy responses. Unlike CGE models, however, ABMs embed more complex decision-making processes in their framework, permitting individual 'agents' to possess differing preferences, attributes and social ties. Drawing on theory and empirical data, simulations are populated with agents programmed to reflect the real-world heterogeneity of potential migrants, making mobility decisions against future risk levels and policy environments. Looking across large numbers of model-level simulations, ABMs offer a view of the migration dynamics that may emerge, mapping out the possibility space of key system-level outcomes. This class of models provides a complement to data-driven parametric models ('what has happened before') and equilibrium modelling approaches ('how we expect things to happen') by mapping out the possibility space of ' what could possibly happen', 'what responses to interventions appear likely', 'what are the pathways that could lead to desired outcomes' and 'what outcomes are not feasible.'

\section{Modelling from the bottom up}

Modelling migratory responses to sea-level change first requires assumptions regarding the risk of exposure in the near term. Physical science models provide insights into the spatial distribution of such risk over time and likely adaptation options. An ABM can be used to predict the characteristics of future migration. Drawing on the kinds of variables typically captured by representative household surveys (such as demographics, assets and livelihood data) and, where available, data on human decision making from behavioural experiments (such as livelihood time allocation and risk preferences), populations of modelled agents can be calibrated to reflect actual population attributes and livelihood portfolios at origins and destinations. In particular, these modelled populations may have varied risk perceptions and sensitivities to the push, pull and mooring factors that tie people to place. ABMs can be programmed to dynamically simulate the probabilistic formation and loss of social network connections that confer migration opportunities and/or act as pull factors to new destinations ${ }^{3}$.

As in the real world, policy levers in an $\mathrm{ABM}$ can be parameterized to shape agents' access to parts of their environment, changing the costs or benefits associated with choices, or change the information landscape that the agents participate in. ABMs have been used as virtual policy laboratories to explore the implications of various interventions on agents, such as changes to flood insurance uptake ${ }^{24}$ or hard versus soft policies for coastal protection ${ }^{25}$, coastal zoning ${ }^{26}$ and communicating coastal risk ${ }^{27}$. Each of these applications demonstrates the importance of individuallevel heterogeneity, which matters in that push-pull feedbacks may result in nonlinear, surprising, emergent migration outcomes.

What emerge from ABM experiments are not point estimates of who will go where and when; rather, ABMs map out the possibility space of different outcomes (including flows and timings of migration). Summaries and comparisons of model outputs can inform planners and policy-makers on migration dynamics that appear inevitable and those that can be influenced, as well as the policy levers that can expand option sets for potential migrants, or narrow the range of likely outcomes.

Whereas past models have not always empirically parameterized key features of simulated agents - their livelihood alternatives, preferences and risk perceptions - advances in mobile-based, high-frequency data collection enable validation experiments on preferences and perceptions at scale for a fraction of the cost of traditional survey research ${ }^{3}$. ABMs can also be calibrated on case studies. These empirical cases provide insights into the primary migration mechanisms to be prioritized in ABM specification, how outcomes such as displacement and migration to new destinations should be calibrated, and the possibility space for surprising dynamics that may emerge over time. It is worth noting that ABM specification from an empirical case of migration at one time and place may not be generalizable for future periods or across contexts. For example, the experience of some small islands - that is, slow social disintegration followed by rapid collapse ${ }^{28}$ - may be a useful analogue, but dynamics in expansive mainland low-elevation coastal zones would be likely to differ.

\section{The path forward}

As a starting point, we recommend that policy-makers apply these models with an emphasis on three important features. First, evaluations of emissions policies under discussion should be prioritized. Models should quantify migration outcomes forced by sea-level rise and extreme sea levels for emissions scenarios corresponding to the long-term objectives of the UN Framework Convention on Climate Change for restricting temperature change to $1.5^{\circ} \mathrm{C}$ and $2{ }^{\circ} \mathrm{C}$ above preindustrial levels ${ }^{29}$, as well as more pessimistic scenarios (for example, RCP 8.5), for outcomes at mid-twenty-first century, 2100 and beyond ${ }^{30}$. Required sealevel data for these scenarios are available at hundreds of locations globally ${ }^{30}$.

Second, with the recognition that a key obstacle to effective climate adaptation is governance failure, in industrialized as well as developing countries, models should simulate migration outcomes for distinct policies that influence individual- and group-level capacity to adapt. This includes policies affecting the general socioeconomic conditions at local and national levels that provide the context for adaptive responses.

Third, analyses should focus on timescales that more closely align with policy processes. Scientists often emphasize the importance of climate and sea-level change projected for 2100 and beyond, with such projections being sensitive to emission scenarios and assumptions about Antarctic ice-sheet physics ${ }^{1,29}$. In the interim, social science models should first concentrate on predicting the migration effects from sealevel change in 2050 when global mean sea- 
level rise is similar under different emission scenarios $^{1,29}$ (Fig. 1a,b). In the second half of this century and beyond, projections of sea-level change increasingly diverge $\mathrm{e}^{1,29,30}$. As we approach this mid-century mark, we should have a better understanding of the emissions and sea-level trajectories that the world will follow for the remainder of the twenty-first century and beyond, and thus be in a better position to account for adaptation interventions and migration in that more distant future (Fig. 1c).

In all cases, representing the feedbacks of policy, population and sea level will be imperative as we build comprehensive models capable of guiding policy. These refinements hinge on the convergence of international organizations, governments, advocacy groups and scholars of various disciplines working to deliver timely and purpose-specific information on coastal risk, adaptation policy and evolving migration dynamics.

\section{J. Wrathall (D) ${ }^{1 \star}$, V. Mueller (D) 2,3 \\ P. U. Clark (D) 1,4 , A. Bell (D) 5 \\ M. Oppenheimer ${ }^{6}$, M. Hauer (D)7 S. Kulp ${ }^{8}$, E. Gilmore (D) ${ }^{9}$, H. Adams (D) ${ }^{10}$, R. Kopp (D) ${ }^{11}$ K. Abel', M. Call ${ }^{12}$, J. Chen ${ }^{13}$, A. deSherbinin ${ }^{14}$, E. Fussell ${ }^{15}$, C. Hay (D) ${ }^{16}$, B. Jones ${ }^{17}$, N. Magliocca D ${ }^{18}$, E. Marino ${ }^{19}$, A. Slangen ${ }^{20}$ and K. Warner2 \\ ${ }^{1}$ College of Earth, Ocean and Atmospheric Sciences, Oregon State University, Corvallis, OR, USA. \\ ${ }^{2}$ School of Politics and Global Studies, Arizona State University, Tempe, AZ, USA. ${ }^{3}$ International Food Policy Research Institute, Washington, DC, USA. ${ }^{4}$ School of Geography and Environmental Sciences, University of Ulster, Coleraine, UK. ${ }^{5}$ Department of Environmental Studies, New York University, New York, NY, USA. ${ }^{6}$ Woodrow Wilson School of Public and International Affairs and Department}

of Geosciences, Princeton University, Princeton, NJ, USA. ${ }^{7}$ Department of Sociology, Florida State University, Tallahassee, FL, USA. ${ }^{8}$ Climate Central, Princeton, NJ, USA. ${ }^{9}$ Department of International Development, Community and Environment, Clark University, Worcester, MA, USA. ${ }^{10}$ Department of Geography, King's College London, London, UK. ${ }^{11}$ Department of Earth and Planetary Sciences, Rutgers University, Piscataway, NJ, USA. ${ }^{12}$ National Socio-Environmental Synthesis Center, Annapolis, MD, USA. ${ }^{13}$ Department of Economics, Ohio State University, Columbus, OH, USA, 43210. ${ }^{14}$ Center for Information Earth Sensing Information Network, Columbia University, Palisades, NY, USA. ${ }^{15}$ Population Studies and Training Center, Brown University, Providence, RI, USA. ${ }^{16}$ Department of Earth and Environmental Sciences, Boston College, Chestnut Hill, MA, USA. ${ }^{17}$ Institute for Demographic Research, City University of New York, New York, NY, USA. ${ }^{18}$ Department of Geography, University of Alabama, Tuscaloosa, AL, USA. ${ }^{19}$ Department of Anthropology, Oregon State University Cascades, Bend, OR, USA. ${ }^{20}$ Department of Estuarine and Delta Systems, NIOZ Royal Netherlands Institute for Sea Research and Utrecht University, Yerseke, the Netherlands. ${ }^{21}$ United Nations Framework Convention on Climate Change, Bonn, Germany. *e-mail:wrathald@oregonstate.edu

Published online: 26 November 2019 https://doi.org/10.1038/s41558-019-0640-4

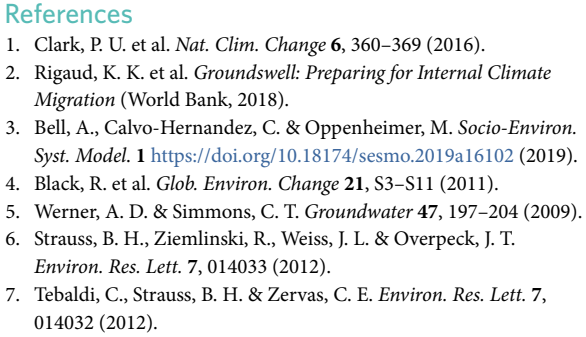

1. Clark, P. U. et al. Nat. Clim. Change 6, 360-369 (2016).

2. Rigaud, K. K. et al. Groundswell: Preparing for Internal Climate Migration (World Bank, 2018).

3. Bell, A., Calvo-Hernandez, C. \& Oppenheimer, M. Socio-Environ. Syst. Model. 1 https://doi.org/10.18174/sesmo.2019a16102 (2019).

4. Black, R. et al. Glob. Environ. Change 21, S3-S11 (2011).

5. Werner, A. D. \& Simmons, C. T. Groundwater 47, 197-204 (2009).

6. Strauss, B. H., Ziemlinski, R., Weiss, J. L. \& Overpeck, J. T. Environ. Res. Lett. 7, 014033 (2012).

7. Tebaldi, C., Strauss, B. H. \& Zervas, C. E. Environ. Res. Lett. 7 014032 (2012)

8. Curtis, K., Fussell, E. \& DeWaard, J. Demography 52 1269-1293 (2015)

9. Bernstein, A., Gustafson, M. \& Lewis, R. J. Financ. Econ. https://doi.org/10.2139/ssrn.3073842 (in the press).

10. Chen, J. \& Mueller, V. Nat. Clim. Change 8, 981-985 (2018).

11. Clemens, M. J. Econ. Persp. 25, 83-106 (2011).

12. Amuedo-Dorantes, C., Puttitanun, T. \& Martinez-Donate, A. Demography 50, 1067-1091 (2013).

13. Ratha, D. Leveraging Remittances for Development. Migration Policy Institute Policy Brief (June 2007).

14. Amirault, D., De Munnik, D. \& Miller, S. Can. J. Econ. 49 1035-1056 (2016)

15. Hallegatte, S. et al. Clim. Change 104, 113-137 (2011). 16. Nicholls, R. J. \& Cazenave, A. Science 328, 1517-1520 (2010).

17. Norfolk's Zoning Ordinance Executive Summary https://www. norfolk.gov/DocumentCenter/View/36605 (accessed 17 May 2018)

18. Adams, H. \& Kay, S. Environ. Sci. Pol. 93, 129-138 (2019).

19. Barnett, J. et al. Nat. Clim. Change 4, 1103-1108 (2014).

20. Healy, A. \& Malhotra, N. Am. Political Sci. Rev. 103 387-406 (2009).

21. Hauer, M. E. Nat. Clim. Change 7, 321 (2017).

22. Desmet, K. et al. Evaluating the Economic Cost of Coastal Flooding. Working Paper no. 24918 (National Bureau of Economic Research, 2018)

23. Arndt, C. et al. Clim. Change https://doi.org/10.1007/s10584-01902428-3 (2019)

24. Jenkins, K., Surminski, S., Hall, J. \& Crick, F. Sci. Tot. Environ. 595, 159-168 (2017)

25. Smajgl, A. et al. Nat. Clim. Change 5, 167 (2015).

26. Filatova, T., Volnov, A. \& van der Veen, A. Environ. Model. Softw. 26, 179-190 (2011).

27. Haer, T., Botzen, W. \& Aerts, J. Environ. Sci. Pol. 60, 44-52 (2016). 28. McLeman, R. A. Glob. Environ. Change 21, S108-S120 (2011). 29. Clark, P. U. et al. Nat. Clim. Change 8, 653 (2018).

30. Oppenheimer, M. et al. in Special Report on Oceans and Cryosphere in a Changing Climate Ch. 4 (IPCC, 2019).

\section{Acknowledgements}

This work was supported by the National SocioEnvironmental Synthesis Center (SESYNC) under funding received from the US National Science Foundation DBI-1639145.

\section{Author contributions}

All authors were involved in the conceptualization of this paper. D.J.W., V.M., P.U.C., M.O., M.H., B.J., S.K., E.G., H.A., A.B. and R.K. were responsible for original drafting and preparation. K.A., M.C., J.C., A.deS., E.F., C.H., B.J., N.M., E.M., A.S. and K.W. reviewed and substantively edited content. D.J.W. and M.H. prepared figures. D.J.W., V.M. and P.U.C. supervised manuscript preparation. All authors were substantively involved in the acquisition of funding.

\section{Climate migration myths}

Misleading claims about mass migration induced by climate change continue to surface in both academia and policy. This requires a new research agenda on 'climate mobilities' that moves beyond simplistic assumptions and more accurately advances knowledge of the nexus between human mobility and climate change.

Ingrid Boas, Carol Farbotko, Helen Adams, Harald Sterly, Simon Bush, Kees van der Geest, Hanne Wiegel, Hasan Ashraf, Andrew Baldwin, Giovanni Bettini, Suzy Blondin, Mirjam de Bruijn, David Durand-Delacre, Christiane Fröhlich, Giovanna Gioli, Lucia Guaita, Elodie Hut, Francis X. Jarawura, Machiel Lamers, Samuel Lietaer, Sarah L. Nash, Etienne Piguet, Delf Rothe, Patrick Sakdapolrak, Lothar Smith, Basundhara Tripathy Furlong, Ethemcan Turhan, Jeroen Warner, Caroline Zickgraf, Richard Black and Mike Hulme
nternational migration and climate policy assumes that anthropogenic climate change already is, and will increasingly be, a major driver of mass migration from the Global South to the Global North. The
UNFCCC explicitly specifies the need to avert, minimize and address climate displacement ${ }^{1}$, while the UN Security Council warns of mass climate migration and the subsequent risk of aggravating

conflicts ${ }^{2}$. Although the potential for climate change to disrupt livelihoods and threaten lives is real, these policies reinforce a false narrative that predicts large numbers of 'climate refugees'. This self-referencing 